\title{
Dose-ranging effects of citrulline administration on plasma amino acids and hormonal patterns in healthy subjects: the Citrudose pharmacokinetic study
}

\author{
C. Moinard ${ }^{1 *}$, I. Nicolis ${ }^{2}$, N. Neveux ${ }^{1,3}$, S. Darquy ${ }^{1}$, S. Bénazeth ${ }^{2}$ and L. Cynober ${ }^{1,3}$ \\ ${ }^{1}$ Laboratoire de Biologie de la Nutrition, EA 2498, Faculté de Pharmacie, Université Paris Descartes, 4 avenue de l'Observatoire, \\ 75270 Paris Cedex 06, France \\ ${ }^{2}$ Laboratoire de Biomathématiques, EA 2498, Faculté de Pharmacie, Université Paris Descartes, 4 avenue de l'Observatoire, \\ 75270 Paris Cedex 06, France \\ ${ }^{3}$ Service de Biochimie, Hôtel-Dieu, AP-HP, 1, Place du Parvis Notre Dame, 75181 Cedex O4 Paris, France
}

(Received 22 February 2007 - Revised 13 August 2007 - Accepted 16 August 2007)

Previous experimental studies have highlighted that citrulline (CIT) could be a promising pharmaconutrient. However, its pharmacokinetic characteristics and tolerance to loading have not been studied to date. The objective was to characterise the plasma kinetics of CIT in a multiple-dosing study design and to assess the effect of CIT intake on the concentrations of other plasma amino acids (AA). The effects of CIT loading on anabolic hormones were also determined. Eight fasting healthy males underwent four separate oral loading tests $(2,5,10$ or $15 \mathrm{~g}$ CIT $)$ in random order. Blood was drawn ten times over an $8 \mathrm{~h}$ period for measurement of plasma AA, insulin and growth hormone (Gh). Urine samples were collected before CIT administration and over the next $24 \mathrm{~h}$. None of the subjects experienced side effects whatever the CIT dose. Concerning AA, only CIT, ornithine (ORN) and arginine (ARG) plasma concentrations were affected (maximum concentration 146 (SEM 8) to 303 (SEM 11) $\mu \mathrm{mol} / \mathrm{l}$ (ARG) and 81 (SEM 4) to 179 (SEM 10) $\mu \mathrm{mol} / \mathrm{l}$ (ORN); time to reach maximum concentration 1.17 (SEM 0.26) to 2.29 (SEM 0.20) h (ARG) and $1 \cdot 38$ (SEM $0.25)$ to 1.79 (SEM 0.11) h (ORN) according to CIT dose). Even at high doses, urinary excretion of CIT remained low ( $<5 \%)$. Plasma insulin and Gh were not affected by CIT administration. Short-term CIT administration is safe and well-tolerated. CIT is a potent precursor of ARG. However, at the highest doses, CIT accumulated in plasma while plasma ARG levels increased less than expected. This may be due to saturation of the renal conversion of CIT into ARG.

Pharmacokinetics: Arginine: Ornithine: Insulin: Growth hormone

Citrulline (CIT) is an amino acid whose name is derived from Citrullus vulgaris (commonly known as watermelon) from which it was first isolated in the $1930 \mathrm{~s}$ (for a recent review, see Curis et $\left.a l^{(1)}\right)$. Until recently, CIT had not attracted much interest in the scientific community because (i) it is a non-proteic amino acid and (ii) it was considered only as an intermediate of the urea cycle ${ }^{(2)}$.

In the early $1980 \mathrm{~s}$, Windmueller \& Spaeth $^{(3)}$ demonstrated that the small intestine releases large amounts of CIT which is mainly taken up by the kidney (of note, CIT is not taken up by the liver) and, in turn, arginine (ARG) was released in amounts equivalent to about $75 \%$ of the CIT taken up. Then, Castillo et al. ${ }^{(4,5)}$ were the first to characterise the CIT and ARG in vivo kinetics at the whole-body level in healthy subjects. These findings allowed the suggestion of an ARG-CIT-ARG inter-organ cycle which can be seen ${ }^{(6)}$ as a mechanism for protecting dietary ARG from excessive liver degradation (because CIT is not taken up by the liver ${ }^{(7)}$ ) and thus maintaining protein homeostasis. Concurrently, it was also demonstrated that CIT was the endproduct of the NO synthase reaction ${ }^{(8)}$.
The role of the intestine as a key regulator of CIT production was further emphasised in situations where intestinal function is altered (i.e. short-bowel syndrome, coeliac disease, radiation-induced intestinal damage, etc $)^{(9-13)}$. In situations where ARG synthesis is compromised, CIT becomes a conditionally essential amino acid ${ }^{(14)}$, thus justifying dietary supplementation with ARG. The specificities of CIT and ARG metabolism combined with the fact that CIT is a major precursor of ARG (through renal conversion) ${ }^{(1,6)}$ led several authors to suggest that CIT might be particularly useful for patients with impaired ARG metabolism ${ }^{(15-19)}$. These data led us to raise the hypothesis that CIT, not ARG, should be administered when intestinal function is compromised. Applying this concept, we recently demonstrated that CIT (but not ARG) increases ARG pools and restores $\mathrm{N}$ balance after massive intestinal resection in the rat ${ }^{(20)}$. Because malnutrition in aged animals leads to gut atrophy ${ }^{(21)}$, we extended the concept to refeeding in old malnourished rats. In this model, CIT supplementation increased protein content in the muscle by stimulating protein synthesis ${ }^{(22)}$. These data form a strong rationale

Abbreviations: ARG, arginine; AUC, area under the curve; CIT, citrulline; $\mathrm{C}_{\max }$, maximum concentration; ORN, ornithine; $\mathrm{t}_{\mathrm{max}}$, time to reach maximum concentration.

* Corresponding author: Dr Christophe Moinard, fax +331 537397 56, email christophe.moinard@univ-paris5.fr 
for conducting clinical trials on the effects of CIT supplementation in short-bowel-syndrome patients or in elderly malnourished patients. However, a prerequisite to any clinical study is the evaluation of the tolerance to CIT loading and the determination of pharmacokinetic parameters (maximum concentration $\left(\mathrm{C}_{\max }\right)$, time to reach maximum concentration $\left(\mathrm{t}_{\max }\right)$, metabolic clearance, etc) in healthy subjects. In this matter, data are scarce and the available articles are either preliminary $^{(23)}$ or suffer limitations ${ }^{(24)}$ as discussed elsewhere ${ }^{(25)}$. The results obtained by administration of its food source (i.e. watermelon) ${ }^{(26)}$ were inconclusive since CIT content in watermelon varies strongly according to species and maturity $^{(27)}$. Several studies have reported that CIT plasma concentration is rapidly increased after oral load ${ }^{(18,28-30)}$, but there is little data available on the transporters involved in intestinal absorption of $\mathrm{CIT}^{(31)}$. Moreover, the absorption of amino acids related to CIT (i.e. ARG and ornithine (ORN)) is low, leading to gastrointestinal side effects (i.e. diarrhoea and vomiting) at relatively high intake levels (i.e. $>10 \mathrm{~g}$ in the bolus) ${ }^{(32)}$ but nothing is known about tolerance to CIT when administered at high dosages.

The aim of the present study was to determine the tolerance and the pharmacokinetic parameters of increasing loads of CIT $(2,5,10$ and $15 \mathrm{~g}$ ) in healthy young subjects, and to investigate the impact on hormonal secretions, since CIT metabolites (for example, ARG, ORN) are known to have strong secretagogue effects ${ }^{(33-35)}$.

\section{Materials and methods}

The study was approved by the ethics committee of the HôtelDieu Hospital (Paris, France). All volunteers gave written informed consent after a full explanation of the study. Enrolment and management of subjects was performed by ASTER (Paris, France), which is a for-profit institution authorised by the French Ministry of Health to perform experiments on healthy volunteers.

\section{Study design}

Subjects. The study was performed on eight young healthy male volunteers (age $27.6 \pm 1.5$ years; BMI $22.3 \pm 0.5 \mathrm{~kg} / \mathrm{m}^{2}$ ). All volunteers were given a medical check-up to ensure they had no acute or chronic diseases or signs of infection and inflammation; none of the subjects were taking any medication liable to affect amino acid metabolism. They were screened by physical examination, blood tests, urinary analysis and electrocardiogram. All volunteers received a normoproteic diet during the week before the beginning of the study and throughout the study.

Protocol. All volunteers received four oral loads consisting of $2,5,10$ or $15 \mathrm{~g}$ CIT administered in random order, each load being separated by a washout period of $15 \mathrm{~d}$. CIT was dissolved into $150 \mathrm{ml}$ water and the solution was drunk rapidly. The glass was washed by $50 \mathrm{ml}$ water which was rapidly drunk by the volunteers. The doses are similar to those used for other related amino acids (i.e. ARG, ORN) in previous pharmacokinetic ${ }^{(34,36)}$ and therapeutic studies ${ }^{(37-39)}$.

Blood samples were drawn before administration (considered as time 0 ) and at 0.25, 0.5, 0.75, 1, 1.5, 2, 3, 5 and $8 \mathrm{~h}$ after the loads. Urine samples were collected in vessels containing antiseptic, during the $0-8 \mathrm{~h}$ period and then at 16 and $24 \mathrm{~h}$ post-administration. Haematological markers (leucocytes, polymorphonuclears, lymphocytes, monocytes, erythrocytes, $\mathrm{Hb})$ and biochemical markers $(\mathrm{Ca}$, total proteins, albumin, C-reactive protein, urea, creatinine, glucose, cholesterol, TAG) were determined before and after the study period. Pre- and post-study clinical examinations were also performed. Safety was evaluated by measurement of arterial pressure and an electrocardiogram was performed before and at 1,2, 4 and $8 \mathrm{~h}$ after CIT administration.

\section{Measurements}

Plasma and urine amino acid concentration. Urine samples taken over the $8 \mathrm{~h}$ were carefully homogenised. Blood and urine samples were rapidly centrifuged and deproteinised with a $30 \%(w / v)$ sulfosalicylic acid solution. The supernatant fractions were stored at $-80^{\circ} \mathrm{C}$ for analysis of amino acids.

Amino acids were separated and quantified by ion exchange chromatography using an amino acid autoanalyser (Amino Tac, JLC-500/V; Jeol Ltd, Tokyo, Japan) with ninhydrin derivatisation $^{(40)}$. Our participation in the European Quality Control Scheme (ERNDIM) indicates the accuracy of our amino acid determinations.

Nitrogen excretion. $\mathrm{N}$ was quantified by chemiluminescence $^{(41)}$ on an Antek 9000 apparatus (Antek, Houston, TX, USA).

Plasma insulin and growth hormone concentrations. These were determined using commercial RIA kits; insulin by a INSIK-5 kit (DiaSorin, Antony France) and growth hormone by an hGH-RIACT kit (Cis-Bio International, Gif-surYvette, France).

Other plasma parameters. Blood samples were rapidly centrifuged, and plasma concentrations of creatinine, $\mathrm{Ca}$ and glucose were determined using an Olympus AU 600 analyser $^{(42)}$.

\section{Pharmacokinetics and statistical analysis}

Plasmatic pharmacokinetic parameters. Pharmacokinetic analysis was performed on the plasma concentration-time data. Pharmacokinetic parameters were estimated using the $\mathrm{R}$ software package (R Foundation for Statistical Computing, Vienna, Austria $\left.{ }^{(4)}\right)$.

Data were analysed with a non-compartmental model with no lag time. The apparent elimination rate constant $\left(k_{e}\right)$ was estimated by non-linear least-squares regression on the last part of the $\mathrm{C}(t)$ curve. A shifted exponential decay model following the equation:

$$
\mathrm{C}(t)=\mathrm{B}+\mathrm{Ae}^{-k_{e} t}
$$

was fitted to the data using a $1 / \mathrm{C}^{2}$ weighting scheme. Three models were tested with the additive constant $\mathrm{B}$ taken either as a fit adjustment parameter, as a constant estimated as the minimum concentration measured for each curve, or as a constant estimated as the mean of the minimum concentrations for each subject. The Akaike ${ }^{(44)}$ information criterion was used to discriminate between models yielding coefficients significant at $P<0 \cdot 01$. The Akaike information criterion based on information theory is useful for comparing models fitted with 
different numbers of parameters and different numbers of data points as it takes into account not only goodness of fit but also degrees of freedom, thus discouraging overfitting. In order to only fit the data when the exponential decay model was valid (i.e. to select the starting time of the 'last part of the curve' used for the non-linear model fitting), a procedure was written in $\mathrm{R}$ programming language to test different time-lengths for the last part of the curve. For each curve we varied the start time of the exponential fit from $0.75 \mathrm{~h}$ to $1.5 \mathrm{~h}$ and the end time from $5 \mathrm{~h}$ to $8 \mathrm{~h}$, which yielded five fits including between five and seven experimental points. The Akaike information criterion was used to select the optimal range to fit each curve.

The area under the curve (AUC) for the time $0-8 \mathrm{~h}$ $\left(\mathrm{AUC}_{0-8}\right)$ was calculated by the trapezoidal rule. The AUC from the last experimental time to infinity $\left(\mathrm{AUC}_{8-\infty}\right)$ was calculated by extrapolation, dividing the last measured plasma concentration value by the apparent elimination rate constant $\left(k_{e}\right)$. The $\mathrm{AUC}_{0-\infty}$ was calculated by adding $\mathrm{AUC}_{0-8}$ and $\mathrm{AUC}_{8-\infty}$. All AUC corrected for baseline concentration, which was taken as the concentration at $\mathrm{t}=0 \mathrm{~h}$, are termed $\Delta \mathrm{AUC}$.

(a)

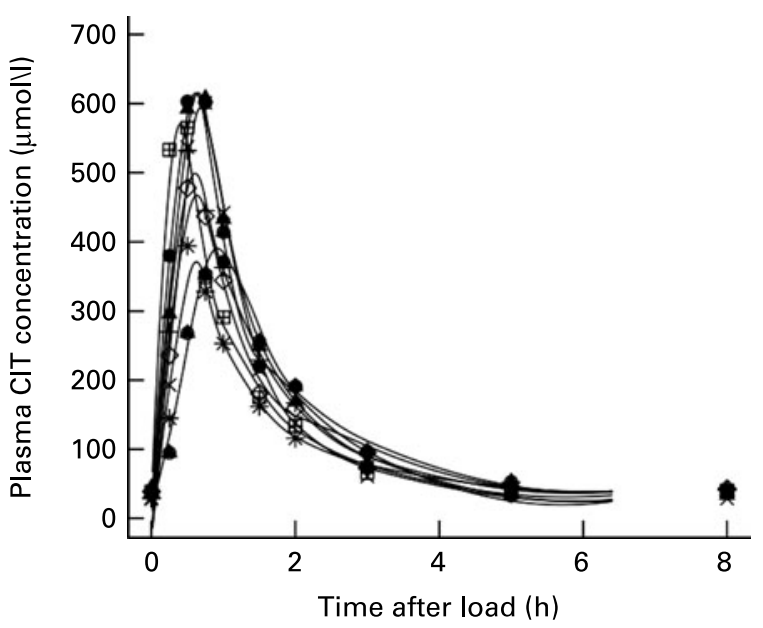

(c)

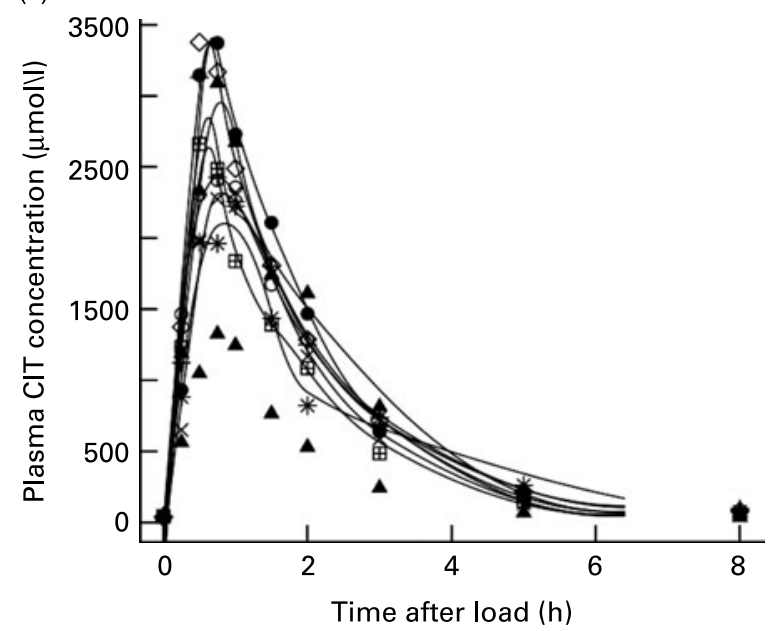

$\mathrm{AUC}_{0-8}$ was smoothed by cubic spline interpolation and the interpolated curve was derived numerically in order to obtain a smoothed $\mathrm{C}(t)$ curve. $\mathrm{C}_{\max }$ and $\mathrm{t}_{\max }$ were deduced from this smoothed $\mathrm{C}(t)$ curve. All $\mathrm{C}_{\max }$ corrected for baseline concentration are termed $\Delta \mathrm{C}_{\max }$.

Clearance $(\mathrm{Cl})$ was evaluated as $\mathrm{Cl}=\operatorname{dose} / \Delta \mathrm{AUC}_{0-\infty}$. Apparent distribution volume $\left(\mathrm{V}_{\mathrm{d}}\right)$ was computed as $\mathrm{Cl} / k_{e}$. The apparent half-life of elimination $\left(\mathrm{t}_{1 / 2}\right)$ was calculated as $\mathrm{t}_{1 / 2}=\ln 2 / k_{e}$

Urinary pharmacokinetic parameters. Renal clearance $\left(\mathrm{Cl}_{\mathrm{R}}\right)$ was computed for CIT and creatinine (CR). Renal clearance $\left(\mathrm{Cl}_{\mathrm{R}}\right)$ of a given solute was estimated as $\mathrm{U} \times \mathrm{V} / \mathrm{P}$ were $\mathrm{U}$ is the solute urine concentration for the $0-8 \mathrm{~h}$ period, $\mathrm{V}$ is the urine flow rate for the same period and $\mathrm{P}$ is the average plasma solute concentration, taken as $\mathrm{AUC}_{0-8} / 8$, with $\mathrm{AUC}_{0-8}$ not corrected for the baseline concentration.

Fractional CIT reabsorption rate $\left(\mathrm{Fr}_{\mathrm{CIT}}\right)$ was computed as:

$$
\mathrm{Fr}_{\mathrm{CIT}}=100\left(1-\frac{\mathrm{Cl}_{\mathrm{R}}(\mathrm{CIT})}{\mathrm{Cl}_{\mathrm{R}}(\mathrm{CR})}\right)
$$

(b)

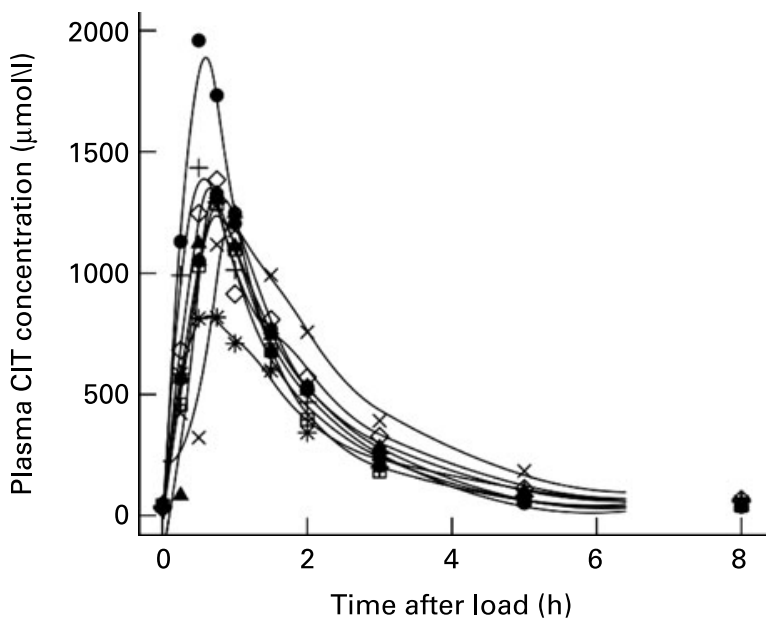

(d)

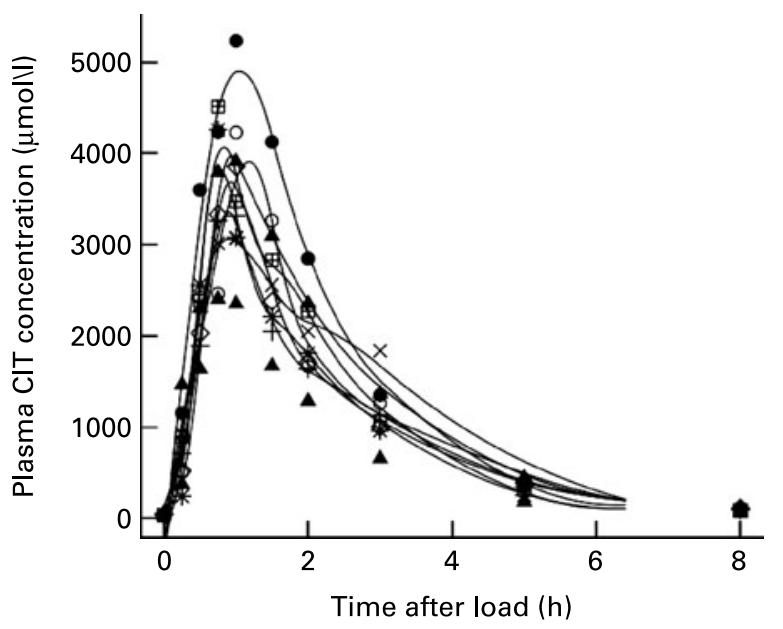

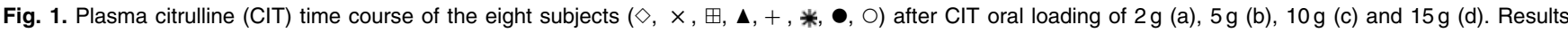
are expressed in $\mu \mathrm{mol} / \mathrm{l}$. Individual measures are shown together with the smoothed lines used for estimation of time to reach maximum concentration ( $t_{\text {max }}$ ) and maximum concentration $\left(\mathrm{C}_{\max }\right)$. 
Retention percentage (RP) of CIT was computed as:

$$
\mathrm{RP}_{\mathrm{CIT}}=100\left(\frac{\operatorname{load}_{\mathrm{CIT}}-\left(\mathrm{U}_{\mathrm{CIT}}+\mathrm{U}_{\mathrm{ARG}}+\mathrm{U}_{\mathrm{ORN}}\right) \mathrm{Q}_{0-8}}{\operatorname{load}_{\mathrm{CIT}}}\right),
$$

where $\mathrm{U}$ is as above and $\mathrm{Q}_{0-8}$ is the urine volume collected during the $0-8 \mathrm{~h}$ period.

Statistical analysis. Three factors were considered for the analysis: dose, patient and period of administration. The experiments followed a double Latin square design assuming an additive model and no interaction between the two squares. Three-factor ANOVA followed by Tukey's honestly significant differences post hoc test was used to estimate effects of each of the three factors on all the above computed plasma or urinary pharmacokinetic parameters. Tests were applied to natural logarithm-transformed values of $\Delta \mathrm{C}_{\max }$, $\triangle \mathrm{AUC}$ and urinary excretion values, in order to homogenise variances.

When ANOVA showed a significant dose effect, dose proportionality was tested and, as shown in the results section, only when a linear relationship was significant. In relation to amino acid metabolism we also tested the $t_{\max }$ values ordering for the three amino acids CIT, ORN and ARG by applying one-sided $t$ tests.

\section{Results}

All eight subjects completed all four trials. There was no dropout or subject replacement.

\section{Tolerance}

None of the volunteers suffered nausea or diarrhoea or any other side effect, whatever the dose.

\section{Safety}

A clinical and biological check-up (see Material and Methods section) was performed in order to evaluate the potential adverse effects of CIT. CIT administration had no effect on haematological or biochemical markers nor on blood pressure (data not shown). Moreover, no clinical symptoms were noticed during the present study (data not shown).

\section{Plasma amino acids}

Citrulline. Following CIT administration, plasma CIT concentration increased to a maximum $\left(\mathrm{C}_{\max }\right)$ then decreased to baseline levels within $3-5 \mathrm{~h}$ (Fig. 1). From the eight sets of volunteer data, $t_{\max }$ remained constant at an average of $42 \mathrm{~min}$ for the 2, 5 and $10 \mathrm{~g}$ loads and shifted to an average $56 \mathrm{~min}$ for the $15 \mathrm{~g}$ load $\left(P=6 \times 10^{-5}\right)$. The $\Delta \mathrm{C}_{\max }$, $\Delta \mathrm{AUC}_{0-8}$ and $\Delta \mathrm{AUC}_{0-\infty}$ of CIT changed significantly with increasing dose $(P<0.001$ after natural logarithm transformation) (Fig. 2). Of note, this increase was not proportional to the load.

CIT clearance was dependent on load in the load range $2-10 \mathrm{~g}(P<0.001)$; however, there were no differences between clearances for the $10 \mathrm{~g}$ and $15 \mathrm{~g}$ doses.

There were no changes in the apparent distribution volume of CIT, whatever the load.
Apparent elimination half-life $\left(\mathrm{t}_{1 / 2}\right)$ increased linearly with increasing doses $(P<0 \cdot 001)$ for the load range $2-15 \mathrm{~g}$ (Table 1$)$.

Arginine and ornithine. After CIT administration, plasma ARG and ORN concentrations increased to reach a maximum (between 1.17 (SEM 0.26) and 2.29 (SEM 0.20) h for ARG and between 1.38 (SEM 0.25) and 1.79 (SEM 0.20) $\mathrm{h}$ for ORN according to CIT load) and then decreased without reaching baseline values at the end of the $8 \mathrm{~h}$ period. Noise and lack of pure exponential decay at the last part of the curve meant that we could not compute elimination constants and thus half-life time, $\Delta \mathrm{AUC}_{0-\infty}$ and clearance for these amino acids. Hence, only $\Delta \mathrm{AUC}_{0-8}, \Delta \mathrm{C}_{\max }$ and $\mathrm{t}_{\max }$ were computed for ARG (Table 2) and ORN (Table 3). Natural logarithms of $\triangle \mathrm{AUC}_{0-8}$ were clearly modified with the load $(P<0 \cdot 001)$, except for ORN under the $15 \mathrm{~g}$ load (Fig. 2), as were natural logarithms of $\Delta \mathrm{C}_{\max }(P<0.001)$, except for $\mathrm{ARG}$ and ORN at the $15 \mathrm{~g}$ CIT load. However, because of noise, a load effect on $\mathrm{t}_{\max }$ could only be detected for ARG $(P=0.007)$ and not for ORN. For each CIT load, $t_{\max }$ was greater for ARG than for CIT $(P=0.04, P=0.0035, P<0.001$ and $P<0.001$ for loads of $2,5,10$ and $15 \mathrm{~g}$, respectively).

Other amino acids. CIT administration led to no significant changes in other amino acid concentrations compared with baseline values (Table 4).
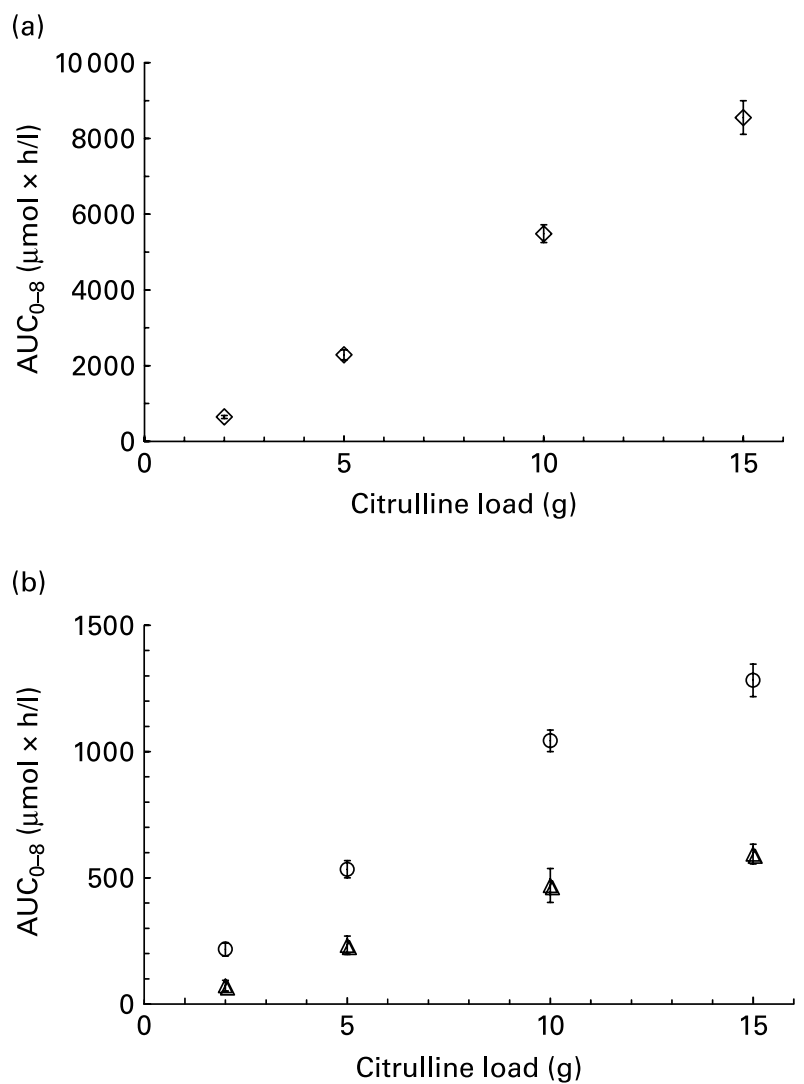

Fig. 2. (a) Areas under the curve for time $0-8 \mathrm{~h}\left(\mathrm{AUC}_{0_{-8}}\right)$ of plasma citrulline $(\diamond)$ concentrations in volunteers who received $2,5,10$ or $15 \mathrm{~g}$ citrulline. (b) $\mathrm{AUC}_{0-8}$ of plasma arginine $(\mathrm{O})$ and ornithine $(\Delta)$ concentrations in volunteers who received 2, 5, 10 or $15 \mathrm{~g}$ citrulline. Results are expressed in $\mu \mathrm{mol} \times \mathrm{h} / \mathrm{l}$. Values are means, with their standard errors represented by vertical bars. For clarity only error bars greater than $100 \mu \mathrm{mol} \times \mathrm{h} / \mathrm{l}$ are shown. 
Table 1. Pharmacokinetic parameters of plasma citrulline after citrulline loads administered to healthy volunteers* (Mean values with their standard errors)

\begin{tabular}{|c|c|c|c|c|c|c|c|c|c|c|c|c|}
\hline \multirow[b]{2}{*}{ Load (g) } & \multicolumn{2}{|c|}{$t_{\max }(h)$} & \multicolumn{2}{|c|}{$\mathrm{C}_{\max }(\mu \mathrm{mol} / \mathrm{l})$} & \multicolumn{2}{|c|}{$t_{1 / 2}(h)$} & \multicolumn{2}{|c|}{$\begin{array}{l}\Delta \mathrm{AUC}_{0-\infty} \\
(\mu \mathrm{mol} \times \mathrm{h} / \mathrm{l})\end{array}$} & \multicolumn{2}{|c|}{ Clearance $(\mathrm{l} / \mathrm{h})$} & \multicolumn{2}{|c|}{$\mathrm{V}_{\mathrm{d}}$ (litres) } \\
\hline & Mean & SEM & Mean & SEM & Mean & SEM & Mean & SEM & Mean & SEM & Mean & SEM \\
\hline 2 & $0.64^{a}$ & 0.05 & $515^{a}$ & 35 & $0.65^{a}$ & 0.03 & $646^{a}$ & 38 & $18 \cdot 2^{a}$ & $1 \cdot 3$ & $17 \cdot 2^{a}$ & 1.6 \\
\hline 5 & $0.71^{a}$ & 0.05 & $1314^{b}$ & 100 & $0.90^{\mathrm{b}}$ & 0.07 & $2305^{b}$ & 130 & $12 \cdot 7^{b}$ & 0.8 & $16 \cdot 3^{a}$ & 1.3 \\
\hline 10 & $0.72^{a}$ & 0.03 & $2756^{c}$ & 170 & $1 \cdot 01^{\mathrm{b}, \mathrm{c}}$ & 0.05 & $5521^{c}$ & 240 & $10 \cdot 5^{\mathrm{b}, \mathrm{c}}$ & 0.5 & $15 \cdot 2^{a}$ & 1.0 \\
\hline
\end{tabular}

$t_{\max }$, Time of maximum concentration; $C_{\max }$, maximum concentration; AUC, area under the curve, $V_{d}$, distribution volume; In, natural log-transformed. a,b,c,d Values within a column with unlike superscript letters are significantly different $(P<0.05)$.

${ }^{\star}$ For details of the parameters explored, see the Statistical analysis section. ANOVA and Tukey's honestly significant differences test were performed on $\mathrm{t}_{\max }, \ln \left(\Delta \mathrm{C}_{\max }\right), \mathrm{t}_{1 / 2}, \ln \left(\Delta \mathrm{AUC}_{0_{-\infty}}\right)$, clearance and $\mathrm{V}_{\mathrm{d}}$.

Hormones. Plasma insulin and growth hormone were not affected by CIT administration, whatever the load (data not shown).

Urinary amino acids. CIT, ARG and ORN excretion increased significantly during the studied period $(0-8 \mathrm{~h})$, and the increases were related to load administered $(P<0 \cdot 001$ after natural logarithm transformation for CIT, ARG and ORN) (Table 5). However, urinary output returned to physiological values later on (i.e. $8-24 \mathrm{~h}$ ) (data not shown).

Mass balance between CIT load and the urinary excretion of CIT, ARG and ORN revealed that only a small fraction of CIT load is excreted, as shown by the retention percentage (98.6$86.7 \%)$. CIT retention was significantly dependent on load $(P<0 \cdot 001)$ (Table 5), decreasing with higher loads.

Fractional CIT reabsorption rate $\left(\mathrm{Fr}_{\mathrm{CIT}}\right)$ was very high $(99.0-91.9 \%)$ and was significantly dependent on load $(P<0.001)$ (Table 5), but decreased with higher loads.

Urinary calcium and nitrogen. CIT administration had no effect on total $\mathrm{N}$ and $\mathrm{Ca}$ excretion (Table 5).

\section{Discussion}

CIT has recently begun to attract attention in clinical nutrition. Indeed, the CIT molecule appears to be an accurate marker of intestinal $^{(45)}$ or renal failure ${ }^{(46)}$. Moreover, experimental results indicate that CIT could be a promising therapeutic

Table 2. Pharmacokinetic parameters of plasma arginine after citrulline loads administered to healthy volunteers*

(Mean values with their standard errors)

\begin{tabular}{|c|c|c|c|c|c|c|}
\hline \multirow[b]{2}{*}{ Load (g) } & \multicolumn{2}{|c|}{$t_{\max }(h)$} & \multicolumn{2}{|c|}{$\mathrm{C}_{\max }(\mu \mathrm{mol} / \mathrm{l})$} & \multicolumn{2}{|c|}{$\begin{array}{c}\Delta \mathrm{AUC}_{0-8} \\
(\mu \mathrm{mol} \times \mathrm{h} / \mathrm{l})\end{array}$} \\
\hline & Mean & SEM & Mean & SEM & Mean & SEM \\
\hline 2 & $1 \cdot 17^{\mathrm{a}}$ & 0.26 & $146^{a}$ & 8 & $217^{a}$ & 26 \\
\hline 5 & $1.44^{\mathrm{a}}$ & 0.20 & $209^{b}$ & 12 & $534^{\mathrm{b}}$ & 34 \\
\hline 10 & $1.67^{a, b}$ & 0.05 & $280^{c}$ & 8 & $1043^{c}$ & 43 \\
\hline 15 & $2 \cdot 29^{b}$ & 0.20 & $303^{c}$ & 11 & $1282^{d}$ & 64 \\
\hline
\end{tabular}

$t_{\max }$, Time of maximum concentration; $C_{\max }$, maximum concentration; AUC, area under the curve; In, natural log-transformed.

$a, b, c, d$ Values within a column with unlike superscript letters are significantly different $(P<0.05)$

* For details of the parameters explored, see the Statistical analysis section ANOVA and Tukey's honestly significant differences test were performed on $\mathrm{t}_{\max }, \ln \left(\Delta \mathrm{C}_{\max }\right)$ and $\ln \left(\Delta \mathrm{AUC}_{0-8}\right)$. agent for promoting protein synthesis ${ }^{(4)}$. However, its safety, tolerance and most appropriate dose need to be determined as a prerequisite to any use in humans ${ }^{(25)}$. The present study clearly showed that CIT is well tolerated (no side effects), and it should be underlined that CIT did not induce gastrointestinal disorders at high dose (i.e. $15 \mathrm{~g}$ ). This latter result is quite surprising because a bolus $(>10 \mathrm{~g})$ of related amino acids such as ORN or ARG usually causes diarrhoea ${ }^{(32,33)}$. It can be explained by rapid saturation of the intestinal absorption of ORN and ARG, which induce osmotic diarrhoea at high loads ${ }^{(32)}$. This difference in behaviour between CIT and ORN and ARG suggests that intestinal absorption of CIT is not a limiting step, even at high CIT loads (i.e. $>10 \mathrm{~g}$ ). Of note, if CIT transport in several cell types (for example, endothelial cells and macrophages) is well characterised in several studies ${ }^{(48,49)}$, intestinal CIT absorption is poorly documented ${ }^{(31)}$. Nevertheless, data discussed above strongly suggest that there may be a specific powerful carrier of CIT. This idea is supported by our recent work (performed using Caco-2 cells) which demonstrated that CIT uptake is mediated by two different mechanisms, one of them being clearly different to classical cationic amino acid transporters and displaying high $\mathrm{V}_{\max }{ }^{(50)}$.

Concerning the safety of CIT after acute administration, a major potential concern is the fact that excretion of amino acids in large amounts in urine is associated with an increase

Table 3. Pharmacokinetic parameters of plasma ornithine after citrulline loads administered to healthy volunteers*

(Mean values with their standard errors)

\begin{tabular}{|c|c|c|c|c|c|c|}
\hline \multirow[b]{2}{*}{ Load (g) } & \multicolumn{2}{|c|}{$t_{\max }(h)$} & \multicolumn{2}{|c|}{$\mathrm{C}_{\max }(\mu \mathrm{mol} / \mathrm{l})$} & \multicolumn{2}{|c|}{$\begin{array}{c}\Delta \mathrm{AUC}_{0-8} \\
(\mu \mathrm{mol} \times \mathrm{h} / \mathrm{l})\end{array}$} \\
\hline & Mean & SEM & Mean & SEM & Mean & SEM \\
\hline 2 & $1 \cdot 38^{a}$ & 0.25 & $81^{\mathrm{a}}$ & 4 & $73^{a}$ & 21 \\
\hline 5 & $1 \cdot 35^{\mathrm{a}}$ & 0.13 & $114^{\mathrm{b}}$ & 9 & $233^{b}$ & 36 \\
\hline 10 & $1.57^{\mathrm{a}, \mathrm{b}}$ & 0.06 & $152^{C}$ & 13 & $470^{c}$ & 67 \\
\hline 15 & $1 \cdot 79^{b}$ & 0.11 & $179^{c}$ & 10 & $594^{c}$ & 39 \\
\hline
\end{tabular}

$t_{\max }$, Time of maximum concentration; $C_{\max }$, maximum concentration; AUC, area under the curve; In, natural log-transformed.

a,b,c Values within a column with unlike superscript letters are significantly different $(P<0.05)$.

${ }^{*}$ For details of the parameters explored, see the Statistical analysis section. ANOVA and Tukey's honestly significant differences test were performed on $t_{\max }, \ln \left(\Delta \mathrm{C}_{\max }\right)$ and $\ln \left(\Delta \mathrm{AUC}_{0-8}\right)$. 
Table 4. Areas under the curve for time $0-8 \mathrm{~h}$ corrected for baseline concentration $\left(\Delta \mathrm{AUC}_{0-8}\right)(\mu \mathrm{mol} \times \mathrm{h} / \mathrm{l})$ of plasma amino acids after citrulline loads in healthy volunteers*

(Mean values with their standard errors)

\begin{tabular}{|c|c|c|c|c|c|c|c|c|}
\hline \multirow{2}{*}{$\begin{array}{l}\text { Load }(\mathrm{g}) . . . \\
\text { Amino acid }\end{array}$} & \multicolumn{2}{|c|}{2} & \multicolumn{2}{|c|}{5} & \multicolumn{2}{|c|}{10} & \multicolumn{2}{|c|}{15} \\
\hline & Mean & SEM & Mean & SEM & Mean & SEM & Mean & SEM \\
\hline Ala & -173 & 170 & -631 & 164 & -645 & 126 & -726 & 190 \\
\hline Asn & -17 & 24 & -41 & 22 & -35 & 13 & -33 & 12 \\
\hline Asp & -2 & 3 & -3 & 4 & 1 & 1 & 1 & 1 \\
\hline Cys & 6 & 20 & -10 & 21 & -28 & 8 & 14 & 12 \\
\hline Gln & -78 & 266 & -328 & 262 & -355 & 118 & 45 & 195 \\
\hline Glu & -2 & 21 & 21 & 20 & -43 & 39 & 23 & 11 \\
\hline Gly & -3 & 97 & -125 & 95 & -164 & 40 & -77 & 75 \\
\hline His & -1 & 39 & -26 & 32 & -28 & 15 & 19 & 21 \\
\hline Ile & -92 & 28 & -100 & 40 & -149 & 23 & -97 & 15 \\
\hline Leu & -38 & 61 & -121 & 78 & -170 & 39 & -87 & 35 \\
\hline Lys & 63 & 91 & 20 & 67 & 42 & 39 & 104 & 49 \\
\hline Met & -6 & 13 & -15 & 12 & -26 & 12 & -10 & 6 \\
\hline Phe & -19 & 27 & -50 & 32 & -54 & 18 & -41 & 19 \\
\hline Pro & -183 & 90 & -299 & 118 & -289 & 106 & -116 & 73 \\
\hline Ser & -16 & 40 & -56 & 61 & -109 & 23 & 0 & 28 \\
\hline Tau & 18 & 19 & 8 & 24 & 15 & 8 & 55 & 18 \\
\hline Thr & -42 & 63 & -87 & 57 & -110 & 25 & -17 & 40 \\
\hline Trp & -34 & 29 & -49 & 24 & -78 & 20 & -46 & 20 \\
\hline Tyr & -70 & 31 & -97 & 41 & -102 & 19 & -69 & 19 \\
\hline Val & -136 & 101 & -198 & 133 & -255 & 58 & -92 & 53 \\
\hline
\end{tabular}

${ }^{*}$ For details of the parameters explored, see the Statistical analysis section. ANOVA and Tukey's honestly significant differences test were used. No statistical difference was observed for any amino acid at any load.

in urinary $\mathrm{Ca}$ loss, and it has been shown that the dose of amino acids administered is correlated with the renal excretion of $\mathrm{Ca}^{(51)}$. This phenomenon may be a problem in the long term because amino acid-induced $\mathrm{Ca}$ loss may be responsible for osteoporosis. In the present study, calciuria remained constant whatever the urinary concentration of CIT, which suggests that CIT administration is not expected to interfere with $\mathrm{Ca}$ homeostasis. Of note, similarly to intestinal absorption, renal CIT reabsorption appears extremely powerful because urinary loss is very low $(<5 \%)$ even at high CIT intake.

Following the CIT loads, plasma CIT concentration increased rapidly and massively (10-fold at the $2 \mathrm{~g}$ load to 100 -fold at the $15 \mathrm{~g}$ load) and returned to baseline values within 5-8 h post-loading.

A review of the literature data indicates that the pharmacokinetic parameters of CIT are similar to those of related amino acids (such as ARG and ORN) ${ }^{(33-35)}$, except for $\mathrm{C}_{\max }$ which is several-fold higher with CIT than with $\mathrm{ARG}^{(36)}$ or $\mathrm{ORN}^{(35)}$. This result is in agreement with a previous study of Rajantie et $a l .{ }^{(23)}$, who observed that CIT loads caused much greater increases in its plasma concentration than equimolar loads of ARG or ORN. This difference is probably related to the specific metabolism of CIT. A large proportion of dietary ARG (or ORN) is extracted during the first-pass splanchnic extraction (ARG is degraded by the intestine to yield ORN and proline ${ }^{(52)}$, and in the liver ARG is a substrate for ureagenesis $(5,29,36,53-55))$. CIT, however, bypasses splanchnic extraction ${ }^{(1,6,7)}$. This explains the very high $\mathrm{C}_{\max }$ values observed in the present study as well as the lack of effect of CIT on $\mathrm{N}$ excretion (despite increasing loads of $\mathrm{N}$ ). Again, the high $\mathrm{C}_{\max }$ may also be explained by efficient intestinal absorption (see above).

The main feature of CIT is to be taken up by the kidney and metabolised into $\mathrm{ARG}^{(56)}$. This is confirmed by the large increase of plasma ARG after CIT administration. However, at the highest dose $(15 \mathrm{~g})$, ARG production was not related to the dose administered (i.e. was lower than expected). Since plasma CIT concentration is the primary factor which determines ARG production by the kidney ${ }^{(14,57)}$, it appears

Table 5. Urinary excretion (0-8h) of citrulline (CIT), arginine (ARG), ornithine (ORN), nitrogen and calcium in healthy volunteers* (Mean values with their standard errors)

\begin{tabular}{|c|c|c|c|c|c|c|c|c|c|c|c|c|c|c|}
\hline \multirow[b]{2}{*}{ Load (g) } & \multicolumn{2}{|c|}{$\mathrm{CIT}(\mu \mathrm{mol})$} & \multicolumn{2}{|c|}{ ARG $(\mu \mathrm{mol})$} & \multicolumn{2}{|c|}{ ORN $(\mu \mathrm{mol})$} & \multicolumn{2}{|c|}{$N(g)$} & \multicolumn{2}{|c|}{$\mathrm{Ca}(\mathrm{mmol})$} & \multicolumn{2}{|c|}{$\mathrm{Fr}_{\mathrm{CIT}}(\%)$} & \multicolumn{2}{|c|}{$\mathrm{RP}_{\mathrm{CIT}}(\%)$} \\
\hline & Mean & SEM & Mean & SEM & Mean & SEM & Mean & SEM & Mean & SEM & Mean & SEM & Mean & SEM \\
\hline 2 & $36^{a}$ & 15 & $16^{a}$ & 5 & $11^{\mathrm{a}}$ & 1 & $3 \cdot 4$ & 0.2 & 1.5 & 0.2 & $99 \cdot 0^{\mathrm{a}}$ & 0.4 & $98 \cdot 6^{a}$ & 0.5 \\
\hline 5 & $382^{\mathrm{b}}$ & 76 & $107^{b}$ & 23 & $16^{\mathrm{b}}$ & 2 & 2.4 & 0.4 & 1.6 & 0.3 & $96 \cdot 8^{a, b}$ & 0.8 & $95 \cdot 8^{a, b}$ & $1 \cdot 2$ \\
\hline 10 & $1534^{\mathrm{C}}$ & 346 & $293^{c}$ & 51 & $21^{\mathrm{c}}$ & 2 & $3 \cdot 3$ & 0.5 & 1.4 & 0.2 & $94 \cdot 6^{\mathrm{b}}$ & 1.3 & $92 \cdot 1^{\mathrm{b}, \mathrm{c}}$ & $2 \cdot 8$ \\
\hline 15 & $3960^{d}$ & 601 & $537^{d}$ & 48 & $34^{d}$ & 4 & $3 \cdot 3$ & 0.3 & 1.4 & 0.1 & $91.9^{c}$ & 1.4 & $86 \cdot 7^{c}$ & $2 \cdot 2$ \\
\hline
\end{tabular}

$\mathrm{Fr}_{\mathrm{CIT}}$, fractional reabsorption rate of $\mathrm{CIT}$; $\mathrm{RP}_{\mathrm{CIT}}$, retention percentage of $\mathrm{CIT}$.

a,b,c,d Values within a column with unlike superscript letters are significantly different $(P<0.05)$

* For details of the parameters explored, see the Statistical analysis section. ANOVA and Tukey's honestly significant differences test were used. 
that renal ARG synthesis becomes saturated. This is confirmed by the increase in urinary ARG excretion and the decrease in both CIT retention percentage and fractional reabsorption rate at this high CIT intake.

It should also be underlined that no other amino acid concentrations were modified by CIT administration, which is in agreement with our previous experimental studies ${ }^{(20,22)}$. This means that CIT is a very 'neutral' amino acid performing a specific job in terms of ARG metabolism.

We also measured hormonal patterns because the results of several studies have shown the ability of CIT to modify plasma insulin levels ${ }^{(22)}$ or stimulate insulin secretion ${ }^{(58)}$. However, we observed no modification of plasma insulin and growth hormone concentrations in the present study. This may be explained by the fact that the volunteers were studied in the fasted state. Of note, it has previously been shown that the secretagogue properties of ORN (as ketoglutarate salt) are more pronounced in the fed state than in the fasted state $e^{(34,35)}$.

In conclusion, the present study in healthy men provides important data on CIT safety and tolerance, which both appear excellent and better than related amino acids (i.e. ARG and ORN), at least in the short term. It would be of interest to perform such a pharmacokinetic study after chronic exposure to CIT because a number of enzymes involved in CIT metabolism may be subject to long-term regulation.

The present pharmacokinetic study confirms our previous experimental data showing that CIT is an excellent ARG precursor at the whole-body level. Finally, the pharmacokinetic parameters suggest that saturation begins to occur at a load of $15 \mathrm{~g}$, and therefore a $10 \mathrm{~g}$ dose should be the most appropriate for use in clinical practice.

\section{Acknowledgements}

The present study was supported by a grant from Laboratoires Biocodex. We warmly thank Dr M. E. Le Guern from Biocodex for her advice on defining the study design.

\section{References}

1. Curis E, Nicolis I, Moinard C, Osowska S, Zerrouk N, Benazeth S \& Cynober L (2005) Almost all about citrulline in mammals. Amino Acids 29, 177-205.

2. Rabier D \& Kamoun P (1995) Metabolism of citrulline in man. Amino Acids 9, 299-316.

3. Windmueller HG \& Spaeth AE (1981) Source and fate of circulating citrulline. Am J Physiol 241, E473-E480.

4. Castillo L, Sanchez M, Vogt J, Chapman TE, DeRojas-Walker TC, Tannenbaum SR, Ajami AM \& Young VR (1995) Plasma arginine, citrulline, and ornithine kinetics in adults, with observations on nitric oxide synthesis. Am $J$ Physiol 268 E360-E367.

5. Castillo L, Chapman TE, Sanchez M, Yu YM, Burke JF, Ajami AM, Vogt J \& Young VR (1993) Plasma arginine and citrulline kinetics in adults given adequate and arginine-free diets. Proc Natl Acad Sci USA 90, 7749-7753.

6. Cynober L, Le Boucher J \& Vasson MP (1995) Arginine metabolism in mammals. $J$ Nutr Biochem 6, 402-413.

7. Drotman RB \& Freedland RA (1972) Citrulline metabolism in the perfused rat liver. Am J Physiol 222, 973-975.

8. Palmer RM, Ashton DS \& Moncada S (1988) Vascular endothelial cells synthesize nitric oxide from L-arginine. Nature 333, 664-666.
9. Crenn P, Vahedi K, Lavergne-Slove A, Cynober L, Matuchansky C \& Messing B (2003) Plasma citrulline: a marker of enterocyte mass in villous atrophy-associated small bowel disease. Gastroenterology 124, 1210-1219.

10. Crenn P, Coudray-Lucas C, Thuillier F, Cynober L \& Messing B (2000) Postabsorptive plasma citrulline concentration is a marker of absorptive enterocyte mass and intestinal failure in humans. Gastroenterology 119, 1496-1505.

11. Gondolesi G, Fishbein T, Chehade M, Tschernia A, Magid M, Kaufman S, Raymond K, Sansaricq C \& LeLeiko N (2002) Serum citrulline is a potential marker for rejection of intestinal allografts. Transplant Proc 34, 918-920.

12. Jianfeng G, Weiming Z, Ning L, Fangnan L, Li T, Nan L \& Jieshou L (2005) Serum citrulline is a simple quantitative marker for small intestinal enterocytes mass and absorption function in short bowel patients. J Surg Res 127, 177-182.

13. Lutgens LC, Deutz NE, Gueulette J, Cleutjens JP, Berger MP, Wouters BG, von Meyenfeldt MF \& Lambin P (2003) Citrulline: a physiologic marker enabling quantitation and monitoring of epithelial radiation-induced small bowel damage. Int J Radiat Oncol Biol Phys 57, 1067-1074.

14. Wakabayashi Y (2004) The glutamate crossway. In Metabolic and Therapeutic Aspects of Amino Acids in Clinical Nutrition, pp. 135-152 [L Cynober, editor]. Boca Raton, FL: CRC Press.

15. Wu G \& Meininger CJ (2000) Arginine nutrition and cardiovascular function. $J$ Nutr 130, 2626-2629.

16. Bansal V, Rodriguez P, Wu G, Eichler DC, Zabaleta J, Taheri F \& Ochoa JB (2004) Citrulline can preserve proliferation and prevent the loss of $\mathrm{CD} 3$ zeta chain under conditions of low arginine. J Parenter Enteral Nutr 28, 423-430.

17. Romero MJ, Platt DH, Caldwell RB \& Caldwell RW (2006) Therapeutic use of citrulline in cardiovascular disease. Cardiovasc Drug Rev 24, 275-290.

18. Waugh WH, Daeschner CW III, Files BA, McConnell ME \& Strandjord SE (2001) Oral citrulline as arginine precursor may be beneficial in sickle cell disease: early phase two results. J Natl Med Assoc 93, 363-371.

19. Akashi K, Miyake C \& Yokota A (2001) Citrulline, a novel compatible solute in drought-tolerant wild watermelon leaves, is an efficient hydroxyl radical scavenger. FEBS Lett 508, 438-442.

20. Osowska S, Moinard C, Neveux N, Loï C \& Cynober L (2004) Citrulline increases arginine pools and restores nitrogen balance after massive intestinal resection. Gut 53, 1781-1786.

21. Farges MC, Vasson MP \& Cynober L (1997) Aging of the small bowel: relationship between morphological and functional changes and protein metabolism. $J$ Nutr Health Aging 1, 17-22.

22. Osowska S, Duchemann T, Walrand S, Paillard A, Boirie Y, Cynober L \& Moinard C (2006) Citrulline modulates muscle protein metabolism in old malnourished rats. Am $J$ Physiol Endocrinol Metab 291, E582-E586.

23. Rajantie J, Simell O \& Perheentupa J (1983) Oral administration of urea cycle intermediates in lysinuric protein intolerance: effect on plasma and urinary arginine and ornithine. Metabolism 32, 49-51.

24. Collins JK, Wu G, Perkins-Veazie P, Spears K, Claypool PL, Baker RA \& Clevidence BA (2007) Watermelon consumption increases plasma arginine concentrations in adults. Nutrition 23, 261-266.

25. Cynober L (2007) Pharmacokinetics of arginine and related amino acids. J Nutr 137, Suppl. 2, 1646S-1649S.

26. Mandel H, Levy N, Izkovitch S \& Korman SH (2005) Elevated plasma citrulline and arginine due to consumption of Citrullus vulgaris (watermelon). J Inherit Metab Dis 28, 467-472.

27. Rimando AM \& Perkins-Veazie PM (2005) Determination of citrulline in watermelon rind. J Chromatogr A 1078, 196-200.

28. Wu G, Knabe DA \& Kim SW (2004) Arginine nutrition in neonatal pigs. J Nutr 134, Suppl. 10, 2783S-2790S. 
29. Urschel KL, Shoveller AK, Uwiera RR, Pencharz PB \& Ball RO (2006) Citrulline is an effective arginine precursor in enterally fed neonatal piglets. $J$ Nutr 136, 1806-1813.

30. Smith HA, Canter JA, Christian KG, Drinkwater DC, Scholl FG, Christman BW, Rice GD, Barr FE \& Summar ML (2006) Nitric oxide precursors and congenital heart surgery: a randomized controlled trial of oral citrulline. J Thorac Cardiovasc Surg 132, 58-65.

31. Vagdagama JV \& Evered DF (1992) Characteristics of L-citrulline transport across rat small intestine in vitro. Pediatr Res 32, $472-478$.

32. Grimble GK (2007) Adverse GI effects of arginine and related amino acids. $J$ Nutr 137, 1693S-1701S.

33. Collier SR, Casey DP \& Kanaley JA (2005) Growth hormone responses to varying doses of oral arginine. Growth Horm IGF Res 15, 136-139.

34. Cynober L, Vaubourdolle M, Dore A \& Giboudeau J (1984) Kinetics and metabolic effects of orally administered ornithine $\alpha$-ketoglutarate in healthy subjects fed with a standardized regimen. Am J Clin Nutr 39, 514-519.

35. Cynober L, Coudray-Lucas C, De Bandt JP, Guéchot J, Aussel C, Salvucci M \& Giboudeau J (1990) Action of ornithine $\alpha$ ketoglutarate, ornithine hydrochloride, and calcium $\alpha$-ketoglutarate on plasma amino acid and hormonal patterns in healthy subjects. J Am Coll Nutr 9, 2-12.

36. Tangphao O, Grossmann M, Chalon S, Hoffman BB \& Blaschke TF (1999) Pharmacokinetics of intravenous and oral L-arginine in normal volunteers. $\mathrm{Br} J$ Clin Pharmacol 47, 261-266.

37. Daly JM, Reynolds J, Thom A, Kinsley L, Dietrick-Gallager M, Shou J \& Ruggieri B (1988) Immune and metabolic effects of arginine in the surgical patient. Ann Surg 208, 512-523.

38. Vaubourdolle M, Cynober L, Lioret N, Coudray-Lucas C, Aussel C, Saizy R \& Giboudeau J (1987) Influence of enterally administered ornithine $\alpha$-ketoglutarate on hormonal patterns in burn patients. Burns 13, 349-356.

39. Barbul A (1995) The use of arginine in clinical practice. In Amino Acid Metabolism and Therapy in Health and Nutritional Disease, pp. 361-375 [L Cynober, editor]. Boca Raton, FL: CRC Press.

40. Neveux N, David P \& Cynober L (2004) Measurement of amino acid concentration in biological fluids and tissues using ionexchange chromatography. In Metabolic and Therapeutic Aspects of Amino Acids in Clinical Nutrition, pp. 17-28 [L Cynober, editor]. Boca Raton, FL: CRC Press.

41. Grimble G (1991) Measurement of elemental nitrogen by chemiluminescence (letter; comment). J Parenter Enteral Nutr $15,696$.
42. Blanc MC, Neveux N, Laromiguiere M, Berard MP \& Cynober L (2000) Evaluation of a newly available biochemical analyzer: the Olympus AU 600. Clin Chem Lab Med 38, 465-475.

43. R Development Core Team (2005) A Language and Environment for Statistical Computing. Vienna: R Foundation for Statistical Computing.

44. Sakamoto Y, Ishiguro M \& Kitagawa G (1986) Akaike Information Criterion Statistics. Dordrecht, The Netherlands: D. Reidel Publishing Company.

45. Curis E, Crenn P \& Cynober L (2007) Citrulline and the gut. Curr Opin Clin Nutr Metab Care 10, 620-626.

46. Levillain O, Parvy P \& Hassler C (1997) Amino acid handling in uremic rats: citrulline, a reliable marker of renal insufficiency and proximal tubular dysfunction. Metabolism 46, 611-618.

47. Moinard C \& Cynober L (2007) Citrulline: a new player in the control of nitrogen homeostasis. J Nutr 137, Suppl. 2, 1621S-1625S.

48. Wu G \& Meininger CJ (1993) Regulation of L-arginine synthesis from L-citrulline by L-glutamine in endothelial cells. Am J Physiol 265, H1965-H1971.

49. Wu G \& Brosnan JT (1992) Macrophages can convert citrulline into arginine. Biochem $J$ 281, 45-48.

50. Bahri S, Zerrouk N, Curis E, et al. (2005) Characterization of L-citrulline transport in human intestinal caco-2 cells. Clin Nutr 24, 630.

51. Bengoa JM, Sitrin MD, Wood RJ \& Rosenberg IH (1983) Amino acid-induced hypercalciuria in patients on total parenteral nutrition. Am J Clin Nutr 38, 264-269.

52. Wu G (1998) Intestinal mucosal amino acid catabolism. $J$ Nutr 128, $1249-1252$.

53. Vaubourdolle M, Jardel A, Coudray-Lucas C, Ekindjian OG, Agneray J \& Cynober L (1988) Metabolism and kinetics of parenterally administered ornithine and $\alpha$-ketoglutarate in healthy and burned animals. Clin Nutr 7, 105-111.

54. Vaubourdolle M, Jardel A, Coudray-Lucas C, Ekindjian OG, Agneray J \& Cynober L (1989) Fate of enterally administered ornithine in healthy animals: interactions with $\alpha$-ketoglutarate. Nutrition 5, 183-187.

55. De Bandt JP, Cynober L, Lim SK, Coudray-Lucas C, Poupon R \& Giboudeau J (1995) Metabolism of ornithine, $\alpha$-ketoglutarate and arginine in isolated perfused rat liver. Br J Nutr 73, 227-239.

56. Morris SM Jr (2006) Arginine: beyond protein. Am J Clin Nutr 83, 508S-512S.

57. Dhanakoti SN, Brosnan JT, Herzberg GR \& Brosnan ME (1990) Renal arginine synthesis: studies in vitro and in vivo. Am J Physiol 259, E437-E442.

58. Nakata $M$ \& Yada $T$ (2003) Nitric oxide-mediated insulin secretion in response to citrulline in islet $\beta$-cells. Pancreas 27, 209-213. 